\title{
Relationship Between Arm Span Measurements and Body Height in Herceg Novi
}

\author{
Katarina Dragutinovic ${ }^{1}$ \\ 'University of Montenegro, Faculty for Sport and Physical Education, Niksic, Montenegro
}

\begin{abstract}
The aim of this study was to examine the height of the body in the Montenegrin adolescents from Hreceg Novi, as well as the relationship between the arm span and the body height, as a possible predictor of body height. The research was carried out on 58 Montenegrin adolescents from the southern region of Montenegro, of which 20 are men of average age $18.10 \pm 0.55$ years and 38 girls of the average age are $17.97 \pm 0.37$ years. Anthropometric measurements were carried out in accordance with the International Society for the Improvement of Kinanthropometry (ISAK) protocol. The correlation between body height and arm span was done by a correlation analysis with a confidence of $95 \%$. Then, a linear regression analysis was performed to examine the degree to which the range of the arm can reliably predict growth. The results show that men adolescents are $183.97 \pm 8.67$ $\mathrm{cm}$ high and have arm span of $185.19 \pm 9.58 \mathrm{~cm}$, while girl adolescents are $168.75 \pm 6.09 \mathrm{~cm}$ high and have arm span of $168.32 \pm 7.20 \mathrm{~cm}$. Compared to other studies, the results have shown that both sexes have made the people of Herceg Novi of the highest peoples than most of the nation across Europe. On the other hand, the range of arm span reliably predicts the height of the body in this part of Montenegro, in both sexes. This research was carried out due to the need to create a special height model for each region in Montenegro.
\end{abstract}

Key words: Body height, Arm Span, Adolescents, Prediction

\section{Uvod}

Opština Herceg Novi nalazi se na krajnjem sjeverozapadnom dijelu Crnogorskog primorja, između $18^{\circ} 25^{\prime}-18^{\circ} 42^{\prime}$ istočne geografske dužine i $42^{\circ} 24^{\prime}-42^{\circ} 32^{\prime}$ sjeverne geografske širine (slika 1). Ukupna površina opštine Herceg Novi iznosi $235.3 \mathrm{~km}^{2}$. Stanovništvo živi u 28 naselja, organizovanih kroz 20 mjesnih zajednica. Prostorni raspored stanovništva je veoma neravnomjeran. Tako, većina stanovnika, preko 50\%, živi u gradu (Igalo, Herceg Novi, Topla, Savina) i gustina naseljenosti na ovim područjima iznosi od 50 do 100 st/ha. Od vangradskih naselja najnaseljenija mjesta su Bijela i Zelenika - 20\% stanovništva. U naseljima duž obale živi $85 \%$ od ukupnog broja stanovnika, a preostalih $15 \%$ čini stanovništvo nastanjeno u zaleđu.

Stanovništvo je veoma heterogeno, a u poslednja tri popisa, primijećen je porast u broju stanovnika. Sada u Herceg Novom živi oko 39000 stanovnika. Etnički sastav, prema pop- isu stanovništva iz 2011. godine, izgleda ovako: Srbi 48.89\%, Crnogorci $33.68 \%$, Hrvati $2.14 \%$, Romi $0.84 \%$, Muslimani $0.52 \%$, Bošnjaci $0.24 \%$, Albanci $0.13 \%$ i ostale manje etničke grupe. U Herceg Novom živi oko 10000 punoljetnih stanovnika, a prosječna starost stanovništva iznosi 38.7 godina (37.5 kod muškaraca i 39.8 kod žena). U naselju ima 4460 domaćinstava, a prosječan broj članova po domaćinstvu je 2.85 . U ovom istraživanju ciljna grupa su bili adolescenti koji predstavljaju 6.1\% ukupnog stanovništva u Herceg Novom.

Istraživanja koja su sproveli evropski antropolozi, ukazuju na činjenicu da su najvisočiji ljudi koji žive u Dinaridima (Pineau, Delamarche, \& Bozinovic, 2005). Kako stanovnici i nacije iz bivše Jugosalvije spadaju u ovu klasifikaciju, vjeruje se da su adolescenti sa juga Crne Gore pri samom vrhu kada je u pitanju visina u Evropi. U našoj zemlji najvisočiji su adolescenti iz centrale regije (muškarci $183.58 \mathrm{~cm}$, žene $169.70 \mathrm{~cm}$ ), zatim iz sjeverne (muškarci $183.01 \mathrm{~cm}$, žene $168.84 \mathrm{~cm}$ ) i na kraju iz

Correspondence:

Montenegro K. Dragutinovic

Sport University of Montenegro, Faculty for Sport and Physical Education, Narodne omladine bb, 81400 Niksic, Montenegro E-Mail: katarinadragutinovic24@gmail.com 


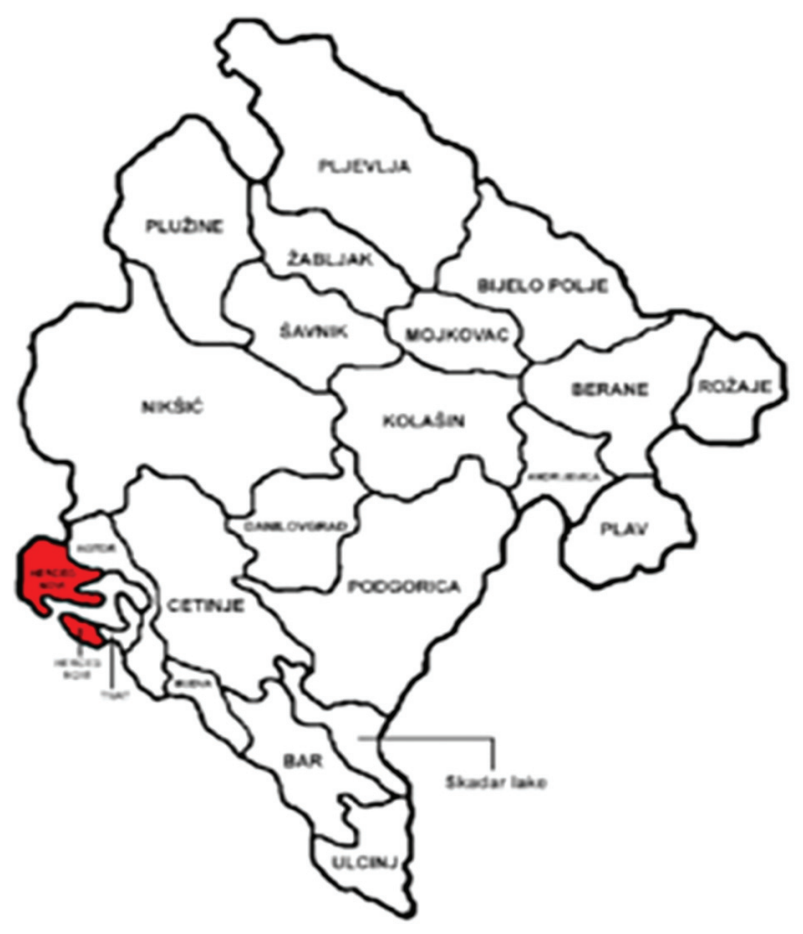

Slika 1. Geografska lokacija Herceg Novog u Crnoj Gori

južne regije (muškarci $182.55 \mathrm{~cm}$, žene $168.76 \mathrm{~cm}$ ) (Popović, 2017).

Postoji veliki broj studija koji potvrđuje da je procjena tjelesne visine značajan faktor koji može uticati na procjenu statusa uhranjenosti kod odraslih ljudi (Arifi, Bjelica, Sermaxhaj, Gardasevic, Kezunovic, \& Popovic, 2017; Popovic, \& Bjelica, 2016), ali i na procjenu razvoja djece, zatim na ocjenu osnovnih energetskih potreba, prilagođavanje mjera fizičkog kapaciteta, kao i procjenu količine uzimanja određenih ljekova i niza drugi stvari, kao što je procjena mišićne snage, mataboličkih procesa, kapaciteta pluća i sl. (Golshan, Amra, \& Hoghogi, 2003; Golshan, M., Crapo, Amra, Jensen, \& Golshan, R. 2007; Mohanty, Babu, \& Nair, 2001; Ter Goon, Toriola, Musa, \& Akusu, 2011).

Kao mnogi od prediktora tjelesne visine koji se pojavljuju u istraživanjima su: raspon ruku, dužina stopala, visina koljena, dužina podlaktice, dužina grudne kosti, sjedjeća visina, dužine lopatice, dužina ruke, kao i niza drugih manje pouzdanih indikatora (Gardasevic, Rasidagic, Krivokapic, Corluka, \& Bjelica, 2017; Popovic, 2017; Masanovic, 2017). Jedan od najpouzdanijih prediktora, koji su potvrdila istraživanja jeste raspon ruku. Međutim, utvrđeno je da su odnosi između tjelesne visine i raspona ruku različiti u različitim etničkim i rasnim grupama (Steele, \& Chenier, 1990; Reeves, Varakamin, \& Henry, 1996; Brown, Feng, \& Knapp, 2002; Bjelica i sar., 2012; Popović, Bjelica, Molnar, Jaksic, \& Akpinar, 2013; Pop- ović, Bjelica, Tanase, \& Milasinovic, 2015; Popovic, Bjelica, Tanase, \& Milasinovic, 2016), dok drugo istraživanje pokazuje da se odnos između raspona ruku i tjelesne visine nelinearno mijenja sa godinama i razlikuje se između dječaka i djevojaka (Quanjer, Capderou, Mazocioglu, Aggarwal, Popovic, Datta Banik, Tayie, Golshan, \& Zelter, 2014).

Cilj ovog istraživanja bio je da se izmjeri tjelesna visina i raspon ruku kod adolescenata Herceg Novog. Odnosno da se utvrdi prosječna tjelesna visina kod oba pola, kao i odnos raspona ruku kao mogućeg prediktora tjelesne visine.

\section{Metod}

Ispitivanje je sprovedeno na uzorku od 58 adolescenata koji žive na teritoriji Herceg Novog. Uzorak je podjeljen na dva subuzorka prema polu, od kojih je 20 muškaraca i 38 djevojaka. Prosječna starost muškaraca je 18.10 \pm 0.55 godina (opseg od 17-19 godina), a djevojaka $17.97 \pm 0.37$ godina (opseg od 17-19 godina).

Kriterijumi za isključivanje iz istraživanja bili su stanovnici koji ne žive na teritoriji Herceg Novog i koji ne pripadaju ovom uzrastu. Takođe, važno naglasiti da ispitanici nisu mogli biti adolescenti sa fizičkim deformitetima koji bi mogli uticati na visinu tijela ili opseg ruku, te takvi nisu bili uključeni u ovo istraživanje. Mjerenje je izvršeno tako što su obučeni mjerioci izmjerili odabrane antropometrijske indikatore, vodeći se pravilima propisanim prema "ISAK priručniku".

Statistička obrada podataka je urađena pomoću softvera Statistical Package for Social Sciences (SPSS). Za obije antropometrijske varijable obrađeni u centralni i disperzivni parametri u okviru osnovne statistike i to: raspon (minimalna i maksimalna vrijednost), aritmetička sredina i standardna devijacija. Diskriminativnom statistikom, odnosno t-testom, su provjerene razlike aritmetičkih sredina antropometrijskih varijabli u odnosu na pol ispitanika. Veza između tjelesne visine i raspona ruku je obrađena korelacionom analizom sa pouzdanošću od $95 \%$. Zatim je izvršena linearna regresiona analiza kako bi se ispitalo koliko raspon ruke može pouzdano predvidjeti tjelesnu visinu. Statistička značajnost je postavljena na $\mathrm{p}<0.05$.

\section{Rezultati}

U tabeli 1 su prikazani rezultati centralnih i disperzivnih parametara ispitanika. Aritmetička sredina za varijablu tjelesna visina kod ispitanika muškog pola iznosi $183.97 \pm 8.67 \mathrm{~cm}$, a u varijabli raspon ruku $185.19 \pm 9.58 \mathrm{~cm}$, što je za $1.22 \pm 0.91$ $\mathrm{cm}$ više. Kod ispitanica aritmetička sredina u varijabli tjelesna visina iznosi $168.75 \pm 6.09 \mathrm{~cm}$, a u varijabli raspon ruku $168.32 \pm 7.20 \mathrm{~cm}$, što je za $0.43 \pm 1.11 \mathrm{~cm}$ manje. Razlike aritmetičkih sredina antropometrijskih varijabli u odnosu na pol ispitanika su statistički značajne. Kada je u pitanju varijabla tjelesna visina sa koeficijentom $\mathrm{t}=7.787 \mathrm{i}$ Sig. $=0.000$, a kod varijable raspon ruku sa koeficijentom $\mathrm{t}=7.556$ i Sig. $=0.000$.

Tabela 1. Centralni i disperzivni parametri antropometrijskih karakteristika

\begin{tabular}{ccc}
\hline \multirow{2}{*}{ Ispitanici } & $\begin{array}{c}\text { Tjelesna visina } \\
(\text { AS } \pm \text { SD) }\end{array}$ & $\begin{array}{c}\text { Raspon ruku } \\
\text { (AS } \pm \text { SD) }\end{array}$ \\
\hline \multirow{2}{*}{ Muški } & $170.2-198.2$ & $171.3-202.8$ \\
& $(183.97 \pm 8.67)$ & $(185.19 \pm 9.58)$ \\
\multirow{2}{*}{ Ženski } & $157.7-181.7$ & $153.1-188.6$ \\
& $(168.75 \pm 6.09)$ & $(168.32 \pm 7.20)$ \\
\hline
\end{tabular}


Rezultati korelacione analize između tjelesne visine i raspona ruku sa pouzdanošću od $95 \%$ za ispitanike oba pola prikazani su u tabeli 2. Povezanost, odnosno korelacija između tjelesne visine i raspona ruku je statistički značajna na nivou
0.000 kod ispitanika oba pola. Dobijeni koeficijenti korelacije su veoma visoki i kod ispitanika muškog pola taj koeficijent iznosi 0.820 , a kod ispitanika ženskog pola 0.826 .

Tabela 2. Korelaciona analiza između tjelesne visine i raspona ruku

\begin{tabular}{cccc}
\hline Ispitanici & Koeficijent korelacije & $\begin{array}{c}\text { Interval pouzdanosti } \\
\text { od 95\% }\end{array}$ & Nivo značajnosti \\
\hline Muški & 0.820 & $0.669-0.912$ & 0.000 \\
Ženski & 0.826 & $0.706-0.917$ & 0.000 \\
\hline
\end{tabular}

Nakon sprovedene linearne regresione analize rezultati su prikazani u tabeli 3. Koeficijenti regresije kod ispitanika oba pola su isti kao i koeficijenti korelacije iz prethodne analize, potvrđujući visok stepen korelacije. Nivo značajnosti kod ispitanika oba pola iznosi 0.000 , što znači da je predikcija raspona ruku na tjelesnu visinu statistički značajna, tj. u odnosu na ras- pon ruku može da se predvidi tjelesna visina kod ispitanika oba pola sa teritorije Herceg Novog. To potvrđuju i koeficijenti determinacije, gdje za muškarce taj koeficijent objašnjava $67.20 \%$ varijabiliteta, a kod djevojaka $68.20 \%$ varijabiliteta, a ostali procenat ostaje neobjašnjen, što nam govori da imamo uticaj drugih faktora koji nisu bili obuhvaćeni ovim istraživanjem.

Tabela 3. Rezultati linearne regresione analize

\begin{tabular}{|c|c|c|c|c|c|}
\hline Ispitanici & $\begin{array}{l}\text { Koeficijent } \\
\text { regresije }\end{array}$ & $\begin{array}{c}\text { Standardna } \\
\text { greška }\end{array}$ & $\begin{array}{c}\text { Koeficijent } \\
\text { determinacije (\%) }\end{array}$ & t vrijednost & Nivo značajnosti \\
\hline Muški & 0.820 & 5.101 & 67.2 & 6.075 & 0.000 \\
\hline Ženski & 0.826 & 3.485 & 68.2 & 8.779 & 0.000 \\
\hline
\end{tabular}

Parametri tjelesne visine i raspona ruku, kao i njihova veza prikazani su udruženo za ispitanike oba pola pomoću skater

dijagrama (slika 2).

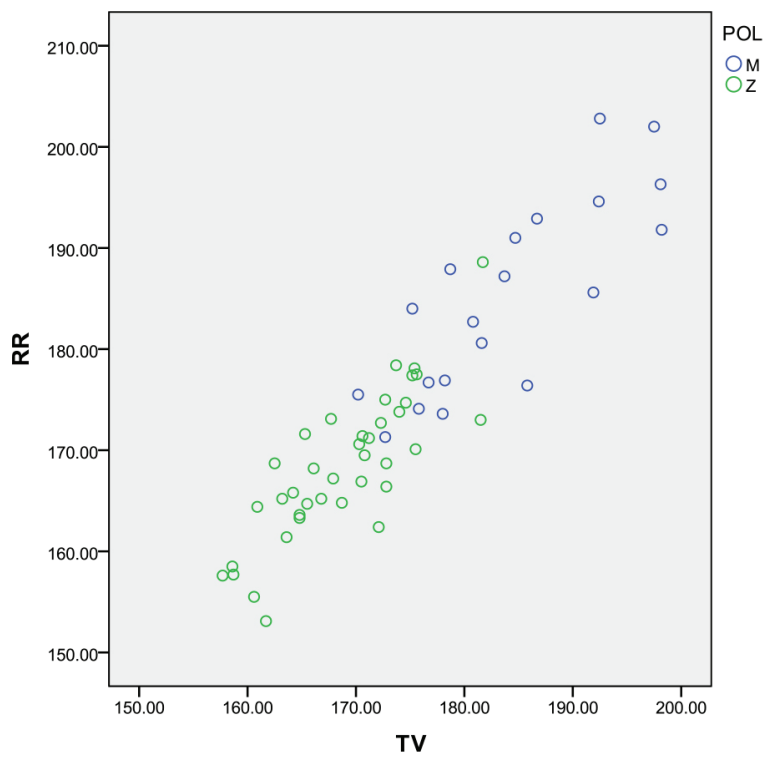

Slika 2. Skater dijagram i veza između raspona ruku i tjelesne visine između oba pola

\section{Diskusija}

Iako je tjelesna visina kod Crnogoraca, u prosjeku porasla tokom XX vijeka, oni ipak više nisu na vrhu ljestvice najvisočijih nacija na svijetu. Prema najnovijim istraživanjima prosječna visina Crnogoraca je $183.36 \mathrm{~cm}$, oni su na drugom mjestu po visini, dok lidersku poziciju drže Holanđani sa $183.8 \mathrm{~cm}$. Rezultati sprovedenih studija potvrdili su pretpostavku da su muškarci i žene u Crnoj Gori među najvišim ljudima na planeti. Međutim, regionalna varijacija je značajna: od $181.25 \mathrm{~cm} \mathrm{u}$ opštini Cetinje do $185.51 \mathrm{~cm}$ u opštinama Kolašin i Šavnik za muškarce, i od $162.53 \mathrm{~cm}$ u opštinama Plav i Andrijevica do $170.86 \mathrm{~cm}$ u opštini Nikšić za žene. Izmjerene vrijednosti visine tijela u Crnoj Gori trenutno su jedne od najviših na svijetu (Popović, 2017; Popović, Bjelica, Milašinović, \& Gardašević, 2016).
Ovo istraživanje obogaćuje prethodna istraživanja kada je $\mathrm{u}$ pitanju odnos tjelesne visine i raspona ruku u Crnoj Gori. Rezultati su pokazali da su muškarci iz Herceg Novog prosječno visoki $183.97 \mathrm{~cm}$, što ih svrastava u u najvisočije među evropskim nacijama. Oni su u vrhu sa Bosancima 183.9 cm (Popović i sar., 2015), a iza sebe su ostavili: Srbe $182.0 \mathrm{~cm}$ (Popović i sar., 2013), Litvance $180.6 \mathrm{~cm}$ (Tutkuviene, 2005), Islanđane $180.6 \mathrm{~cm}$ (Dagbjartsson, Thorsson, Palsson, \& Arnonsson, 2000), Hrvate $180.5 \mathrm{~cm}$ (Juresa, Musilj, \& Tiljak, 2012), Slovence $180.3 \mathrm{~cm}$ (Starc, \& Strel, 2011), Čehe (Vignerova, Brabe, \& Blaha, 2006), i mnoge druge nacije. Što se tiče suprotnog pola, prosječna visina kod djevojaka iz Hereg Novog je $168.75 \mathrm{~cm}$, i ovaj rezultat je pokazao da su djevojke iz Crne Gore pri samom vrhu u poređenju sa drugim zemljama. 
Ispred njih su se našle djevojke iz Bosne $171.8 \mathrm{~cm}$ (Popović i sar., 2015) i Holandije $168.8 \mathrm{~cm}$.

Istraživanja koja su sprovedena na jugu Crne Gore kada je u pitanju muški pol, pokazala su prosječnu visinu 182.53 $\pm 7.53 \mathrm{~cm}$, i u poređenju sa drugim studijama, rezultati ove studije pokazali su da je ovaj pol učinio primorce visokom populacijom, višom od većine nacije širom Evrope (Milasinovic, Popovic, Matic, Gardasevic, \& Bjelica, 2016a; Popović, Milašinović, Matić, Gardašević, \& Bjelica, 2016). Što se tiče suprotnog pola, istraživanja na jugu Crne Gore su pokazala podudarnost sa dobijenom prosječnom visinom i ona iznosi $168.73 \pm 6.79 \mathrm{~cm}$, koji takođe pokazuje da su primorke jedne od najviših u Evropi (Milasinovic, Popovic, Jaksic, Vasilejvic, \& Bjelica, 2016b; Popović, Milašinović, Jakšić, Vasiljević, \& Bjelica, 2016). Rezultati koji su dobijeni na teritoriji opštine Bar, ukazuju na to da su oni nešto niži od Novljana kada je u pitanju muški dio uzorka $182.13 \mathrm{~cm}$, dok je kod ženskog pola suprotna situacija, tj. Baranke su sa prosječnom visinom $168.95 \mathrm{~cm}$ nešto više od Novljanki.

Imajući u vidu postojanje različitih prediktora tjelesne visine, sprovedena su mnoga istraživanja kod nas i u državama u okolini. Na teritoriji Kosova istraživao se uticaj dužine tibije kao mogućeg prediktora tjelesne visine (Gardasevic, Masanovic, Arifi, 2018a; Gardasevic, Masanovic, Arifi, 2018b; Gardasevic, Masanovic, Arifi, 2018c), kao i povezanost dužine tibije sa tjelesnom visinom (Gardašević, 2018a, Masanovic, 2018b). Ovo područje je bilo pogodno za dalja istraživanja, pa su tako ispitane: povezanost tjelesne visine sa sjedjećom visinom u svim regijama (Gardašević, 2018b; Masanovic, 2018a; Masanovic, Gardasevic, \& Arifi, 2018e; Masanovic, Gardasevic, \& Arifi, 2018f; Masanovic, Gardasevic, \& Arifi, 2018g), dužina stopala kao mogući prediktor tjelesne visine (Masanovic, 2018c; Masanovic, Gardasevic, \& Arifi, 2018a; Masanovic, Gardasevic, \& Arifi, 2018b; Masanovic, Gardasevic, \& Arifi, 2018c; Masanovic, Gardasevic, \& Arifi, 2018d; Popovic, Arifi, \& Bjelica, 2017a; Popovic, \& Bjelica, 2017; Popovic, Gardasevic, Masanovic, Arifi, \& Bjelica, 2017b). Pored toga što su sva navedena istraživanja potvrdila prediktivan uticaj, mora se naglasiti da nijedan od navedenih nije dovoljno pouzdan kao raspon ruku, što se pokazalo kao dosljedan rezultat kod nas (Popovic,2016; Milašinović, Popović, Bjelica, \& Vasiljević, 2016), a i u državama regiona (Popovic, \& Bjelica, 2016; Popović, Bjelica, Petković, Muratović, \& Georgiev, 2014; Popović, Bjelica, Milašinović, Gardašević, \& Rašidagić, 2016).

Raspon ruku kao jedan od najpouzdanijih prediktora tjelesne visine u ovom istraživanju je bio kod muškaraca 185.19 $\mathrm{cm}$, što je za $1.22 \mathrm{~cm}$ više od prosječne visine. Dok, kod suprotnog pola imamo raspon ruku $168.32 \mathrm{~cm}$ i to je $0.44 \mathrm{~cm}$ manje. Očekivano, raspon ruku predviđa visinu tijela kod adolesenata koji žive u Hereg Novom. Prethodna istraživanja koja su se sprovela u južnom dijelu Crne Gore ukazala su na različite jednačine procjene $u$ opštoj populaciji, kod muškog pola $2.03 \mathrm{~cm}$ je raspon bio veći, a kod žena $1.50 \mathrm{~cm}$ manji. Što potvrđuje potrebu za izradom posebnih modela visine za svaki dio u Crnoj Gori (Milašinović i sar., 2016a).

Najnovije istraživanje koje su sproveli Bjelica i sar. ističe je da je raspon ruku bio 2.5 centimetra veći od visine $\mathrm{za} \mathrm{cr}$ nogorske dječake (101.4\%), dok je kod crnogorskih djevojaka ova razlika iznosila samo 0.24 centimetra, ali je u prilog rastu (99.9\%). Zatim, Popović i sar. (2013), napomenuo je da je raspon ruku bio 2.8 centimetara veći od visine za srpske dječake (101.5\%), dok je za devojke iz Srbije ova razlika bila samo 0.15 cm (98.7\%). Popović i sar. (2015), takođe su primijetili da je raspon ruku bio za 0.73 centimetra veći nego visina za bosanskohercegovačke dječake (100.3\%), dok je za bosanskohercegovačke djevojčice ova razlika bila manja za $1.97 \mathrm{~cm}$ (98.9\%). Popović i sar. (2016), takođe su potvrdili da je raspon ruku bio za 0.68 centimetara veći od rasta za makedonske dječake (100.4\%), dok je kod makedonskih devojaka ova razlika bila samo 0.17 centimetra (99,9\% ). Quanjer i sar. (2014), istakli su da se procenti predviđenog raspona ruku i visine, mogu razlikovati čak do deset procenata od stvarne visine. Sve ovo dovodi do potrebe za izradom odvojenih modela za svaku regiju, zbog etničkih razlika. Neke od najnovijih studija su utvrdile regionalne razlike između istih etničkih grupa, što zahtijeva dodatni oprez prilikom ovih istraživanja (Vujovic, Bubanja, Tanase, \& Milasinovic, 2015; Milasinović i sar., 2016a).

Rezultati korelacije koji se javljaju primjenom linearne regresione analize upućuje nas na to da postoji visok stepen povezanosti raspona ruku sa tjelesnom visinom, odnosno da možemo na osnovu raspona ruku predvidjeti nečiju visinu. Rezultati prethodnih istraživanja takođe su veoma slični korelaciji dobijenoj u ovom istraživanju (muškarci: $r=0,820$; djevojke: $r=0,826)$. S obzirom na to da je korelacija između raspona ruku i tjelesne visine bila visoka i značajna za oba pola, čini se da je mjerilo raspona ruku pouzdan indirektni antropometrijski indikator za procjenu visine kod oba pola hercegnovskog stanovništva. Iako su ovi odnosi slični, jednačine procjene, koje se dobijaju kod stanovnika Crne Gore, ukazuju nam na potrebu za izradom odvojenih modela izrade za oba pola u svim gradovima Crne Gore. Dalja istraživanja bi trebalo da se odvijaju po principu regionalne podjele zemlje i na taj način utvrditi da li postoje geografske razlike koje utiču na prosječnu visinu kod oba pola, ali i njenu povezanost sa rasponom ruku.

Svrha ovog istraživanja bila je da se utvrdi prosječna tjelesna visina kod stanovnika južne regije u Crnoj Gori, tačnije u Hereg Novom, kao i njena povezanost sa rasponom ruku kod oba pola. Dobijeni rezultati su potvrdili činjenicu da su Crnogorci među najvisočijim nacijama u svijetu, kao i to da raspon ruku ima prediktivnu vrijednost kada je u pitanju tjelesna visina. Ovi rezultati će poslužiti za dalja istraživanja i upoređivanja sa ostalim regijama u Crnoj Gori kako bi se utvrdio odnos između istih, ali i da provjeri da li možda geografske razlike utiču na rezultate.

\section{Acknowledgements}

There are no acknowledgements.

\section{Conflict of Interest}

The authors declare that there are no conflict of interest.

Received: 18 March 2018| Accepted: 01 May 2018| Published: 13 July 2018

\section{References}

Arifi, F., Bjelica, D., Sermaxhaj, S., Gardasevic, J., Kezunovic, M., \& Popovic, S. (2017). Stature and its Estimation Utilizing Arm Span Measurements in Kosovan Adults: National Survey. International Journal of Morphology, 35(3), 1161-7.

Bjelica, D., Popovic, S., Kezunovic, M., Petkovic, J., Jurak, G., \& Grasgruber, P. (2012). Body Height and Its Estimation Utilising Arm Span Measurements in Montenegrin Adults. Anthropol. Noteb., 18(2), 69-83.

Brown, J.K., Feng, J.Y., \& Knapp, T.R. (2002). Is self-reported height or arm span a more accurate alternative measure of height? Clin. Nurs. Res., 11(4), 417- 32.

Dagbjartsson, A., Thorsson, A. V., Palsson, G.I., \& Arnorsson, V.H. (2000). Height and weight of Icelandic children 6-20 years of age. Laeknabladid, 
86(7), 509- 14

Gardasevic, J., Rasidagic, F., Krivokapic, D., Corluka, M., \& Bjelica, D. (2017) Stature and Its Estimation Utilizing Arm Span Measurements in Male Adolescents from Herzeg-Bosnia Entity in Bosnia and Herzegovina. Montenegrin Journal of Sports Science and Medicine, 6(1), 37-44.

Gardasevic, J., Masanovic, B., Arifi, F. (2018). Relationship Tibia Length/Standing Height in Central-Kosovan Adolescents. Retrieved from SSRN's eLibrary: https://ssrn.com/abstract=3138122

Gardasevic, J., Masanovic, B., Arifi, F. (2018a). Relationship Tibia Length/Standing Height in Northern-Kosovan Adolescents. Retrieved from SSRN's eLibrary: https://ssrn.com/abstract=3138112

Gardasevic, J., Masanovic, B., Arifi, F. (2018b). Relationship Tibia Length/Standing Height in Southern-Kosovan Adolescents. Retrieved from SSRN's eLibrary: https://ssrn.com/abstract=3138105

Gardasevic, J. (2018). Standing Height/Tibia Length Ration in Western-Kosovan Adolescents. Retrieved from SSRN's eLibrary: https://ssrn.com/ abstract $=3138101$

Gardasevic, J. (2018a). Standing Height/Sitting Height Ration in Eastern-Kosovan Adolescents. Retrieved from SSRN's eLibrary: https://ssrn.com/ abstract $=3141566$

Golshan, M., Amra, B., \& Hoghogi, M. A. (2003). Is arm span an accurate measure of height to predict pulmonary function parameters? Monald Arch. Chest. Dis., 59(3), 189-92.

Golshan, M., Crapo, R.O., Amra, B., Jensen, R.L., \& Golshan, R. (2007). Arm span as an independent predictor of pulmonary function parameters: validation and reference values. Respirology, 12(3), 361-6.

Juresa, V., Musil, V., \& Tiljak, M.K. (2012). Growth charts for Croatian school children and secular trends in past twenty years. Coll. Antropol. 36(Suppl. 1) 47-57.

Masanovic, B. (2017). Relationship between arm span measurements and body height in Dinaric Alpes population: A systematic review. Journa of Anthropology of Sport and Physical Education, 1(1), 33-37.

Masanovic, B. (2018). Standing Height and its Estimation Utilizing Arm Spam and Foot Length Measurements in Dinaric Alps Population: A Systematic Review. Sport Mont 16(2), 1-6.

Masanovic, B. (2018b). Tibia Length and Standing Heigh Relationshipt in Eastern Region of Kosovo. Retrieved from SSRN's eLibrary: https://ssrn. com/abstract=3143118

Masanovic, B., Gardasevic, J., \& Arifi, F. (2018a). Relationship between foot length measurements and body height: A prospective regional study among adolescents in eastern region of Kosovo. Sport Mont, 16(1), 9-13. doi: $10.26773 / \mathrm{smj}$.180202

Masanovic, B., Gardasevic, J., \& Arifi, F. (2018b). Relationship between Foot Length Measurements and Body Height: A Prospective Regional Study among Adolescents in Northern Region of Kosovo. Anthropologie-International Journal of Human Diversity and Evolution, in pres, https:// doi.org/10.26720/anthro.18.01.23.1

Masanovic, B., Gardasevic, J., \& Arifi, F. (2018c). Relationship between Foot Length Measurements and Body Height: A Prospective Regional Study among Adolescents in Central Region of Kosovo. Journal of Contemporary Medical Sciences, in press

Masanovic, B., Gardasevic, J., \& Arifi, F. (2018d). Standing Height and its Estimation Utilizing Foot Length Measurements in Adolescents from Southern Region in Kosovo. Sport Mont, 16(2), in press

Masanovic, B. (2018a). Standing Height/Sitting Height Relationhip in We stern Region in Kosovo. Retrieved from SSRN's eLibrary: https://ssrn com/abstract $=3138518$

Masanovic, B., Gardasevic, J., \& Arifi, F. (2018e). Sitting Height/Standing Height Relationship in Southern Region of Kosovo. Retrieved from SSRN's eLibrary: https://ssrn.com/abstract=3138523

Masanovic, B., Gardasevic, J., \& Arifi, F. (2018f). Sitting Height/Standing Height Relations in Central Region of Kosovo. Retrieved from SSRN's eLibrary: https://ssrn.com/abstract=3138525

Masanovic, B., Gardasevic, J., \& Arifi, F. (2018g). Sitting Height/Standing Height Relationship Measurements in Northern Region of Kosovo. Retrieved from SSRN's eLibrary: https://ssrn.com/abstract=3138526

Milašinović, R., Popović, S., Bjelica, D. \& Vasiljević, I. (2016). Body height and its estimation utilizing arm span measurements in female adolescent from northern region in Montenegro. In Book of Abstracts of 4th International Scientific Conference "Exercise and Quality of Life" (39), Novi Sad: Faculty of Sport and Physical Education.

Milasinovic, R., Popovic, S., Matic, R., Gardasevic, J., \& Bjelica, D. (2016a). Body Height and its Estimation Utilizing Arm Span Measurements in Male Adolescents from Southern Region in Montenegro. Sport Mont, 14(2), $21-3$

Milasinovic, R., Popovic, S., Jaksic, D., Vasilejvic, I., \& Bjelica, D. (2016b). Stature and its Estimation Utilizing Arm Span Measurements in Female Adolescents from Southern Region in Montenegro. Sport Mont, 14(3), 15-8.
Mohanty, S.P., Babu, S.S., \& Nair, N.S. (2001). The use of arm span as a predictor of height: A study of South Indian women. J. Orthop. Surg. (Hong Kong), 9(1), 19-23.

Quanjer, P.H., Capderou, A., Mazocioglu, M.M., Aggarwal, A., Popovic, S Datta Banik, S., Tayie, F.A.K., Golshan, M., Ip, M.S.M., \& Zelter, M. (2014). All-age relationship between arm span and height in different ethnic groups. European Respiratory Journal, 44, 905-12.

Pineau, J.C., Delamarche, P., \& Bozinovic, S. (2005). Average height of adolescents in the Dinaric Alps. C. R. Biol., 328(9), 841-6.

Popovic, S. (2016). Body Height and its Estimation Utilizing Arm Span Measurements in Montenegrin Adults: National Survey. In Book of Summaries of 11th FIEP European Congress "Anthropological Aspects of Sport, Physical Education and Recreation" (5-6), Banjaluka: University of Banjaluka, Faculty of Physical Education and Sport.

Popovic, S. (2017). Local Geographical Differences in Adult Body Height in Montenegro. Montenegrin Journal of Sports Science and Medicine, 6(1), 81-87.

Popovic, S., Arifi, F., \& Bjelica, D. (2017a). Standing Height and its Estimation Utilizing Foot Length Measurements in Kosovan Adults: National Survey. International Journal of Applied Exercise Physiology, 6(2), 1-7.

Popovic, S., \& Bjelica, D. (2016). Body Height and its Estimation Utilizing Arm Span Measurements in Kosovan Adolescence: National Survey. In Abstract Book of International Eurasian Conference on Sport, Education, and Society (9), Antalya: International Science Culture and Sport Association

Popovic, S., \& Bjelica, D. (2017). Body Height and its Estimation Utilizing Foot Length Measurements in Kosovan Adults: National Survey. In Abstract Book of the Sport Science Conference AESA 2017 (2), Amol: Faculty of Sport Sciences, Shomal University; Asian Exercise and Sport Science Association

Popovic, S., Bjelica, D., Georgiev, G., Krivokapic, D., \& Milasinovic, R. (2016). Body Height and its Estimation Utilizing Arm Span Measurements in Macedonian Adults. Anthropologist, 24(3), 737-745

Popovic, S., Bjelica, D., Molnar, S., Jaksic, D., \& Akpinar, S. (2013). Body Height and Its Estimation Utilizing Arm Span Measurements in Serbian Adults. International Journal of Morphology, 31(1), 271-279.

Popovic, S., Bjelica, D. Tanase, G.D. \& Milasinovic, R. (2015). Body Height and Its Estimation Utilizing Arm Span Measurements in Bosnian and Herzegovinian Adolescents. Montenegrin Journal of Sports Science and Medicine, 4(1), 29-36.

Popovic, S. Gardasevic, J., Masanovic, B., Arifi, F., \& Bjelica, D. (2017b). Standing Height and its Estimation Utilizing Foot Length Measurements in Adolescents from Western Region in Kosovo. Sport Mont, 15(3), 3-7.

Popović, S., Bjelica, D., Petković, J., Muratović, A. \& Georgiev, G. (2014). Body Height and Its Estimation Utilizing Arm Span Measurements in Macedonian Adolescents. In Abstract Book of the 7th Conference for Youth Sport (40), Ljubljana: Faculty of Sport, University of Ljubljana.

Popović, S., Milašinović, R., Matić, R., Gardašević, J., Bjelica, D. (2016). Body height and its estimation utilizing arm span measurements in male adolescents from southern region in Montenegro. In Book of Abstracts of the 13th International Scientific Conference on Transformation Process in Sport "Sport Performance" (29-30), Podgorica: Montenegrin Sports Academy.

Popović, S., Milašinović, R., Jakšić, D., Vasiljević, I., Bjelica, D. (2016). Body height and its estimation utilizing arm span measurements in female adolescents from southern region in Montenegro. In Book of Abstracts of the 13th International Scientific Conference on Transformation Process in Sport "Sport Performance" (30), Podgorica: Montenegrin Sports Academy.

Popović, S., Bjelica, D., Milašinović, R., \& Gardašević, J. (2016). Body height and its estimation utilizing arm span measurements in male adolescents from northern region in Montenegro. In Book of Abstracts of 4th International Scientific Conference "Exercise and Quality of Life" (38), Novi Sad: Faculty of Sport and Physical Education.

Popović, S., Bjelica, D., Milašinović, R., Gardašević, J., \& Rašidagić, F. (2016). Body height and its estimation utilizing arm span measurements in male adolescents from Herzeg-Bosnia entity in Bosnia and Herzegovina. In Book of Abstracts of IUAES Inter Congress "World anthropologies and privatization of knowledge: engaging anthropology in public" (148), Dubrovnik: International Union of Anthropological and Ethnological Sciences.

Popovic, S. \& Bjelica, D. (2016). Body Height and its Estimation Utilizing Arm Span Measurements in Kosovan Adolescence: National Survey. In Abstract Book of International Eurasian Conference on Sport, Education, and Society (9), Antalya: International Science Culture and Sport Association.

Reeves, S.L., Varakamin, C., \& Henry, C.J. (1996). The relationship between armspan measurement and height with special reference to gender 
and ethnicity. Eur. J. Clin. Nutr., 50(6), 398-400.

Starc, G., \& Strel, J. (2001). Is there a rationale for establishing Slovenian body mass index references of school-aged children and adolescents? Anthropol. Noteb., 17(3), 89-100.

Steele, M.F., \& Chenier, T.C. (1990). Arm-span, height, and age in black and white women. Ann. Hum. Biol., 17(6), 533-41.

Ter Goon, D., Toriola, A.L., Musa, D.I., \& Akusu, S. (2011). The relationship between arm span and stature in Nigerian adults. Kinesiology, 43(1), 38-43.
Tutkuviene, J. (2005). Sex and gender differences in secular trend of body size and frame indices of Lithuanians. Anthropol. Anz., 63(1), 29-44.

Vignerová, J., Brabec, M., \& Bláha, P. (2006). Two centuries of growth among Czech children and youth. Econ. Hum. Biol., 4(2), 237-52.

Vujovic, D., Bubanja, M., Tanase, G.D., \& Milasinovic, R. (2015). Body height and its estimation utilizing arm span measurements in male adolescents from Central Region in Montenegro. Sport Mont., 12(43-45), 283-8. 